\title{
Crowding-Out Effects of Government Guided Venture Philanthropy
}

\section{-A Case Study of Z City}

\author{
Shuxuan Li \\ Graduate School of Public Administration and Emergency Management, Jinan University, Guangzhou, China \\ Email: understand1016@qq.com
}

How to cite this paper: Li, S.X. (2018) Crowding-Out Effects of Government Guided Venture Philanthropy. American Journal of Industrial and Business Management, 8, 433-445.

https://doi.org/10.4236/ajibm.2018.83028

Received: February 12, 2018

Accepted: March 5, 2018

Published: March 8, 2018

Copyright $\odot 2018$ by author and Scientific Research Publishing Inc. This work is licensed under the Creative Commons Attribution International License (CC BY 4.0).

http://creativecommons.org/licenses/by/4.0/ (c) (i) Open Access

\begin{abstract}
Venture Philanthropy means providing the social organizations with monetary support and instruction of skills and management to build up their own capacity. But the Venture Philanthropy guided by the Government adds too much external interference to the VP projects selection and evaluation. Through reviews and observations with participants of Z City Venture Philanthropy Competitions, I found that social organizations had to adjust themselves to the rules in order to obtain the approval of rules. And this caused the "crowding out" of voluntary and individuality of the social organizations.
\end{abstract}

\section{Keywords}

Venture Philanthropy, Governance of the Government, Social Organization, Crowding-Out

\section{Introduction}

Crowding-out effects in the public sector occur frequently. Crowding-out effect is a phenomenon that external influence put on collective activity will disturb its internal operational mechanism, change its mission and then crowd out its autonomy. Crowding-out effect can be expressed in many ways, and Sievers called it "investor control [1]", which means that investor will replace the target of the investee with its own requirements and goals. Ostrom once conducted an in-depth analysis of Taiwan's case [2]. In the early 1990s, for the consideration of the political votes from the peasants, government undertook the cost of routine maintenance and operation of the drains which used to be undertaken by 17 irrigation associations. With disappearing of the "sweet burden" and transferring 
of responsibility for the drains, peasants no longer voluntarily pay or work for the drain and its surrounding ecological environment. The irrigation costs did not fall but increased sharply, eventually resulted in great wasting of resources. Ostrom argued that external incentives, especially material incentives could generate adjustment of short-term behavior, but once the individual found that his or her own autonomy and self-esteem were negatively affected, their intrinsic motivation would diminish, internal composition of rules and financing services approach would be suppressed, relationship originally based on voluntary would no longer exist.

Comparing with the case above, we will find that "venture philanthropy" (VP) is a way to invest in start-up and small or medium-sized social organizations, external incentives exist frequently during the developing of operation mode. What's more, comparing with traditional charity donation, VP will offer both financial support and instruction of technology and administration; In order to find out potential capacity of fund-raising and professional capacity building, VP emphasizes investor's participation with social organizations rather than the one-off payment. If relationship between investor and investee was not clear and mechanism of moderately external incentives was not specified, the goal displacement from investor (government, enterprise, foundation, etc.) to investee (social organization) would always happen.

The earliest VP in China started in 2006 by the Lenovo Group who funded nearly 3 million for its Lenovo Venture Philanthropy Plan, and the earliest government-guided VP practice started in 2009 by the Shanghai Municipal Civil Affairs Bureau allocated 10 million welfare lottery funds for the Shanghai Community Venture Philanthropy Competition. Government funding has strong sustainability, the fund source is stable, the VP target is set for pure social interests and the credibility is strong enough to attract social resources. Because of all these advantages, government-guided VP is becoming the main practice model of VP. As a way to cultivate and stimulate the social organizations, VP has gradually been recognized by the national policy. Larger to VP led by provincial and municipal civil affairs departments, smaller to mini-VP led by community, VP is blossoming everywhere in China. What's more, comments on VP are almost purely positive.

Although some scholars and grassroots social organization staff found that social organizations have to cope with different kinds of assessment, they're not so keen on participating and their project is not so creative but just regular. Problems like those have came to be noticed, but not been analyzed from a theoretical perspective yet. They're always thought to be outcome of conceptual confusion between VP and government purchase, but the crowding-out effect from over-control of government were not mentioned. Z City Social Organization Venture Philanthropy Competition has stepped to the fourth session, makes some innovation and forms useful experience. This paper takes Z City Social Organization Venture Philanthropy Competition as an example to analyze the 
performance of crowding-effect in VP and the specific impact of government guidance on voluntary. The aim is to put forward my own opinion in the background of one-side praise to VP.

\section{Literature Review}

VP derived from 1990s of America. It is generally believed that the earliest definition of "VP" comes from the essay named "Virtuous capital" by Letter, Ryan and Grossman, published on the "Harvard Business Review" in 1997 [3]. It described that the project orientation and short term of the traditional charity donation pattern will cause a number of projects which were initially assessed for high quality ultimately failing to meet expectations due to their limit organization capacity. And it claims that "Venture Capital Investment" pattern would be a better way to promote the capability of non-profit organization, and eventually compared VP pattern with traditional charity donation pattern from six respects: risk management, performance measures, closeness of relationship, amount of funding, length of the relationship, the exit. The latest definition given by the European Association for Venture Capital (EVPA) in 2017 was that "Venture philanthropy addresses the growing need for support and flexible funding. Through three core practices, VP offers an effective, high-engagement and long-term approach to supporting SPOs in generating social impact".

Depending on the different development stage of NGO, venture philanthropy in China has to adjust its implementation. After visiting some American NGO like CfA (Code for America), Chinese scholar ZHU Zhaonan summarized that VP in America has characters like embrace venture \& encourage creativity, growth accompany \& participate, build up ecosystem and research \& practice successful pattern [4]. Meanwhile creativity, long-term supporting, capability cultivation are exactly weak points of VP practice in China. Still remaining some traditional charity donation features, VP in China is always thought as mixed pattern which is adjusted according to reality [5]. For example, the fund of VP always comes from welfare fund or government funding. In order to make sure it's used safely and effectively, only low-risk livelihood projects could be approved, like helping elderly, disabled people, low-income family $\&$ teenager. Additionally, limited by government funds billing cycle, VP supporting period is always short than 1 year. Except for primary preparation, mid-term \& final project evaluation, time for project implementation is really short. Last but not least, relationship between government and funded NGOs is not able to be really equal. Without comprehensive pre-survey for the need of civil society \& start-up NGOs, some funded NGOs have to adjust themselves to meet requirements of government. Therefore relationship between government and funded NGOs is not like cooperative governance.

Research on crowding-out effect starts from phenomenon of government funds crowded out individual donation. Titmuss [6] found that more blood was donated in the voluntary system. Sievers believed that the core value of NGO as 
one social capital member is aiming straightly at the social community without affection from government and market will. Therefore intervention and engagement from investors which play the role of assistance initially will gradually disrupt the independence of NGOs and control them finally. Carlson [7] found that even if foundation investors could control their intervention(such as require to be part of council), they would still look over their investment and keep the impulse for participating and supervising the project from planning to implement. And NGOs will doubt if themselves or foundation investors are the one who make final decisions. Gentis [8] defined "crowding-out effect" that after adding momentary incentives to activity which was set up voluntarily, hypothetical donation increments was offset by crowded-out donation amount, which means the actual results even worsened. Three conditions under which the crowding-out effect of pro-social behaviour is likely to occur and crowd out citizens' moral obligations to behave cooperatively were mentioned by literal study: the nature of external intervention (controlling vs. supportive external intervention), the degree of participants self-determination (high vs. low self-determination in the group), norms of trust and reciprocity (high vs. Low trust within the society). Vollan [9] examined those three conditions through field study on several South Africa and Namibia villages. Jacobsen [10] thought "if external interventions (such as command systems and financial incentives) are perceived to be controlling, they are more likely to crowd out intrinsic motivation". Huges [11] analyzed the data from annual reports of the League of American Orchestras from 2004 to 2007, and found the negative and significant impact fund raising efforts from government support. Ostrom believed crowding-out effect will not only waste human and the other resources but also threaten citizens' participation passion, highly centralized governance system is not a panacea that addresses the issue of collective action. Public policymakers should recognize the existence of different kinds of individuals, balance coercive and service/values policies and establish a multi-center system.

In summary, investor should dig out the true needs of investee and have a good knowledge of its internal development mechanism in order to make incentives positive. On one hand, setting up rules to limit investees' activity, may cause chaos inside the development system and investees' "reverse psychology". On the other hand, investees who are not able to or not willing to protest would adjust themselves to rules, which means giving up their own individual position. Both these two situations are not good for investees to improve their capability and the situation, the "kind" investment may cause "bad" results. In the background of government guidance, VP has a tendency of standardization for project designing and evaluation, that may be more convenient for getting VP projects copied as government purchasing, but the advantage of NGO like reaching more diversity society needs, serving social service more flexibly and creatively, couldn't function well, some NGOs will even transform to be kind of government department. 
We took Z City Venture Philanthropy Competition as example and analyzed the response of social organizations to government regulation to prove the existence and results of "crowding-out effect".

\section{Background and Operation Measures of Z City VP Practice}

In the China mainland, the earliest and remarkable VP practice is "Lenovo Venture Philanthropy Plan" which was sponsored by Lenovo Group and designed by NPI. 3 million RMB was used to support 16 NGOs all over the country in one year. In May 2009, Shanghai Community Venture Philanthropy Competition which was organized by Shanghai Municipal Civil Affairs Bureau and undertaken by Shanghai Pudong NPI open the path of government dominating practice. As a professional incubator for nonprofit organizations, NPI plays a critical role in the undertaking of two different VP practices. This novel way attracted many local governments to have a try. Even though specific measures vary from place to place, but the reference to Shanghai practice still can be seen.

On May $1^{\text {st }} 2014$, Z City Civil Affairs Bureau hosted the first Venture Philanthropic Competition of $Z$ City. The third-party social organization undertook the project selection, training, project evaluation \& project acceptance (See Table 1 for details). 15 million municipal welfare lottery fund was used for project funding. The maximum funding amount per project is 300,000 yuan. The total number of projects is not less than 50 and the funding period is "generally less than one year". Support stops while the project period ends. NGOs registered in Z City have access to project selection, departments (enterprises or governments) and individuals have no qualification. "Elderly people, disabled people, youth, low-income family related projects \& the others"-those five categories were allowed to apply. And projects should meet the requirements of "charity related, extensively demanded, innovative in methods, exemplary, professional". The fund that each project could get was $60 \%$ of the project budget which was verified and confirmed by the expert team (not exceeding 300,000 yuan), and the remaining $40 \%$ must be raised by the NGO. The $4: 6$ mandatory standard was used

Table 1. General situation of Z City VP competition.

\begin{tabular}{cccc}
\hline $\begin{array}{c}\text { Period } \\
\text { (from project } \\
\text { selection to } \\
\text { conclusion) }\end{array}$ & Organizer & Hoster & $\begin{array}{c}\text { Fund Amount Funded project } \\
\text { (million yuan) }\end{array}$ \\
\hline amount
\end{tabular}

Source of data: website of Civil Affairs Bureau. 
to stimulate the potential of attracting more society investment. Z City Civil Affairs Bureau issued " $Z$ City NGO Venture Philanthropy Project Management Approach" [12] as an ordinance for the entire VP activities to clear responsibilities and priorities at all stages of activities. After receiving the funding, the organizer will also organize one expert team to supervise the implementation stage \& results of the project, and the use of funds. Projects with problem will face rectification and even the funds will be recovered. It can be seen that the practice of $Z$ City still keeps the main features of the past government-guided VP, and shows a trend of standardization.

\section{Creativeness and Disputes of Z City}

Firstly, Mandatory ratio of $60 \%$ given fund and $40 \%$ self-raised fund. 15 million yuan was used for driving the 10 million yuan of society supporting capital, that creative measure aimed for stimulating the enthusiasm of fund-raising for NGOs. In a certain extent, it also represents the difference between VP and traditional charity donation. However, self-raising is really hard for some smallscale NGOs who want to perform real deeds. They may be stuck by the threshold of entry, or continue to apply with ignoring the fact that they couldn't raise enough money. Even if their project could be selected, things wouldn't go well during implementation [13]. Joint solicitation fund-raising platform was introduced in the third Z City Venture Philanthropy Competition. In accordance with the "Z City Fund-raising Regulations", the host organized NGOs to apply for fund-raising permits, aimed for attracting more society donation for VP projects through individual and enterprise fund-raising platforms. However, limited by the immature development stage, the peak of donation only appeared on the first day when the project is on-line, and the amount of donation and the number of visitors are relatively fragmented.

Secondly, "others" category was set to explore diverse social needs. Common project categories of "elderly people, disabled people, youth, low-income family" were set up by the earliest Shanghai Community Venture Philanthropy Competition. The earliest VP practice of Guangdong Province-First Dongguan Venture Philanthropy Activity also contains categories of "elderly people, disabled people, youth, low-income family". Compared to the past VP practice, Z City VP added the "others" category, and the proportion of "other" category showed an upward trend in the successive years, reserving space for more and more diverse society needs. But actually, "others" category was mainly projects of "social worker training" and "research on NGO" related projects which could receive a big deal of fund per project. The so-called "others" couldn't explore too many other society needs at all.

Finally, "Top Ten Brands" and "Top Ten Excellent Projects" were introduced as a benchmark for good projects. Being rated as "Brand" or "Excellent" will bring higher reputation to NGOs and will bring them great convenience for being selected as VP project in the next year. In addition, being rated as "Brand" or 
"Excellent" could become a stepping stone for NGOs to attract more social resources, reach a cooperation with enterprises or undertake more government purchasing services. Controversy at this point is whether the "Brand" or "Excellence" projects had sufficient ability of growing as well as before after the completion of VP and withdrawal of government funds, and whether the selection of "Brand" and "Excellent" covered the real ability requested by sustainable development.

\section{Crowding-Out Effect in Z City VP Practice}

Z City Venture Philanthropy Competition was led by the Z City Civil Affairs Bureau. Through the process of project applying, project selection, welfare fund allocation, project implementation and final evaluation, NGOs was pushed to discover their potential in project planning, implementation, finance standardization \& social resource linking. In the third Z City Venture Philanthropy Competition, measures like joint communication, joint investment, joint solicitation fund-raising and joint training were promoted to achieve more social benefits. Uniting Government, Market \& NGO for social governance is exactly the " $1+1+1>3$ " concept of Z City VP mode. And the forth Z City Venture Philanthropy Competition had also been officially launched on March 2, 2017, and focused on the "elderly people" related projects. With the continuous accumulation of VP experience and a substantial increase in the amount of funds, in order to ensure the use efficiency of the Welfare Fund, both the project selection and evaluation have grown a trend of standardization. NGOs both have certain expectations and driven interests in VP, including "money", "reputation", "social concern", “ability improvement", “attracting more government purchase" and other needs. While facing the standardized project designing requirements and evaluation criteria, different NGOs may make different choices:

\section{Cause of Crowding-out Effect}

\section{- Non-participate}

Departments (enterprises or governments), individuals and the grassroots NGOs which not registered in the Civil Affairs Bureau were already blocked by the door. Furthermore, the setting of project category \& selection criteria and the rigid ratio of $40 \%$ self-raising fund also made some NGOs give up. Even NGOs which can meet the standards didn't have enough enthusiasm to participate. 941 NGOs submitted annual reports on online registration platform in 2015, and 569 NGOs got ranked different levels, 56 of them got the 5A level. Meanwhile, only 372 NGOs participated the third Z City Venture Philanthropy Competition, and 154 of them were finally funded. Obviously, VP competition was not so attractive to NGOs [14].

\section{- Participate}

Small \& mid-sized and start-up NGOs that choose to participate in VP may treat this an unique opportunity of enhancing interaction with the government and exercising their own ability of projecting. However, under the guidance of 
the government, both project application and implementation are kind of limited, due to consideration of reducing the risk of wasting welfare fund. Top-down project designing and performance appraisal standards limited NGOs of different types by one common constraint. Inevitably, this would subtly guide NGOs to strike a balance between doing projects freely and standards compliant. Frumkin argues that there was no evidence that could prove the oblivious relation between quantitative assessment of social returns and the development of philanthropy. Limitation on social returns rate should be as less as possible. Otherwise, VP will only be valued by short-term returns [15].

If one NGO choose to participate in VP but treat it negatively, the project quota and money would be wasted, and the VP couldn't play its due role.

If participate, NGOs have to adjust their own internal operating mechanism and mission vision to meet various requirements under guidance of the government. And the price they cost is mission shifting and loss of individuality.

When worked as a worker of third-party social organization, I found that some NGOs did really well in VP project, but gave little attention to the standardization of finance and keeping data. This may hinder them from getting high scores in the final evaluation, will also affect their next round apply. Obviously, there is a huge gap between the target set by the government for VP and the true willingness of NGOs themselves, and their mission would be hard to avoid from making compromises to different degrees. As Ostrom argues, if donor's will of self-realization was limited by series of reward and punishment provisions, the contract based on voluntary would turn into a pure business contract and the intrinsic motivation of donor would got weakened. And this change of donation will crowd out donors, the crowding out effect will be particularly obvious in condition of unfair restraints.

\section{Performance of Crowding-out Effect}

The essential purpose for the government initiating VP is playing NGOs' advantage of flexibility, creativity, closeness to grassroots society and encouraging them to develop diverse projects that could meet various social needs and improve citizen's happiness, so that NGOs would also become more able to undertake social services. Therefore, less restrictions at the beginning of the project selection could stimulate the creativity of NGOs, they could also find more subtle social needs.

On the contrary, short-term, multi-batch and standardized assessment would make the internal development mechanism of start-up and small \& medium NGOs get strongly disrupted by policy tendency. In addition, it is very difficult for NGOs to obtain real partnership with the government in the specific stage of development of NGOs in China. Therefore, in order to obtain the approval of rules, NGOs have to adapt themselves to the rules. When the voluntary of NGOs are crowded out, VP projects may become gradually homogenized, NGOs' mission got drifted and they grow to be a government subsidiary.

- In the aspect of development stage, the beforehand requirements and policies 
would disrupt the internal growth mechanism of small \& medium sized and start-up NGOs.

Just like before, VP project period of Z City is also within one-year. Involved NGOs need to deal with the project application, activity preparation, performance evaluation in the middle and final periods, heavy clerical work and cumbersome evaluation process would take up workers, material resources, time and energy of NGO, small organizations are even more tired to deal with that. In addition, I learned from conversations with the involved NGOs that they could not get money immediately after passing the audit, subjecting to cumbersome government approval appropriation procedures, and this would also effect the project schedule. And when the mid-time project evaluation came, participants just began the project for a short time, and it did not take too long for them to cope with the final evaluation. For the participants with less staff, they had to deploy full-time workers or hire temporary interns to cope with the heavy clerical work and cumbersome evaluation. What's most important, little time and energy were left for the project implementation, it is really difficult to guarantee project quality. Some NGOs argue that it is better to give up participating many activities that cost them so much time to cope with clerical works and evaluation, and do their daily routine step by step.

- In the aspect of different target object of different projects, designing projects that cater to the regulations but the NGOs are not good at may lead to the homogeneity of NGOs' development trajectory, that's not good for diggingout deep social needs.

In order to ensure the social benefits, VP practice guided by the government usually requires the social needs of the project should be broad. Taking Z City as an example, only projects comply with the standard "Broad social needs: the social problems that the project addresses and the social needs involved are broad, and the project could keep the good influence over a long period of time after it was implemented" could be selected. The original intention is to ensure that those projects were able to be replicated in other communities or service areas even if they stop getting funds from VP anymore and prevent the preliminary infrastructures from getting wasted due to the weakening social needs, the waste of welfare funds could also be avoided. However, I learned from observation that the "Broad social needs" always got misinterpreted. Although the organizers highlighted before project selection and during training and guidance to NGOs that the selected NGOs should dig-out neglected social needs but not "setting up" new nursing homes, rehab centres or government departments, However, some of them still could not differentiate VP from the government purchase services, regarded the broadness as the regions project covered, communities they served, number of brochures they delivered, phone numbers they got from service receiver. Actually, in the progress of telephone interviews, many recorded telephone number of "service receiver" could not be connected, or the telephone number owner said they had no impression for the project. By the way, many 
people they were not participating into the new round of activities. Generally speaking, the short-term support projects are less transformed into the long-term driving force for the development of NGOs.

Moreover, due to the different project positioning, even projects in the same category need primary inputs with many differences. Take the second VP competition as an example, two "teenager" related Golden prize projects-Cross Fire Line project for teenager fire control experience and Summer Camp of Z City Higher Education Mega Center for left-behind children. The Cross Fire Line not only spread fire control knowledge and organized fire control exercise to a larger extent, but also developed exclusive courses and a mature training system for communities, schools and enterprises to purchase [16]. But the Summer Camp of $Z$ City Higher Education Mega Center was planned for special people whose physical and mental health needs more professional care. Especially, left-behind children need a long time to accept a strange adult out of instinct, and services for children in different age need different focus points. Therefore, project for left-behind children has a slower response than the project for fire control experience and has more professional requirements for social workers. In other words, even serving the social community of same category, requirements for the capabilities of NGOs are different. Moreover, for the projects that require a large amount of pre-inputs, it is certainly difficult to sustain with VP funds only and it's very important to publicize the project to attract more social resources through the government. Evaluating them with other projects that take effect immediately is obviously not conducive to the improving of their ability. For example, project " $Z$ City Community Emergency Rescue Volunteer Service Station" of the first VP competition had built 25 stations before applying for VP project, the cost per station is 100,000 yuan, 300,000 yuan can not help it a lot, and it is also very difficult to evaluate the project because the station was built for preventing risks. It is reported that this project is not listed in the last two VP project lists. Moreover, due to the lack of subsequent government support and the maintenance of professional volunteer groups, emergency rescue stations are not well known among communities.

- In the aspect of different mission between support and operating organizations, the mission of support organizations to link social resources and build the social organizations network is replaced by ordinary social services, subject to the limitations of project categories and performance evaluation standards.

Support organization means this kind of social organization serve other social organizations rather than some social communities. They are also called "Bridging Organization [17]" and "Umbrella Organization [18]". Its mission is to "cultivate the ability of working together to solve social problems [19]", mobilize resources of the government, the market and the other organizations, provide technical, information and management training supports, and promote the capacity of other social organizations. Some support organizations have an official 
background or are born out of government departments, rely on high-end educational organizations as their think tanks to undertake research projects, or play the role of incubator to cultivate and incubate other social organizations. And some of them was operating organizations, and later transformed into support type and focused on research or incubating operating organizations like them before. Compared with other grassroots NGOs, support organizations have a higher starting point. As a platform linking the government with other NGOs, support organizations locate in the middle and upper reaches of the vertical system of the third sector.

Decided by its background, support organizations have higher credibility and are more likely to be favored by the government to purchase services. Therefore, support organizations have more advantages from normative paperwork like project declarations to linking with social resources than operating organizations. Particularly, under the realistic conditions that a $40 \%$ self-raising money, support organizations have innate advantages that are unmatched by operating organizations.

Based on those above differences, it can be said that support and operate organizations are born with different missions. Through the process of doing VP projects, ability of NGO will be enhanced. The preferences of two kind NGOs involved in venture philanthropy are not exactly the same, and the improvement of the ability gained through venture philanthropy is either not same. For example, if knowledge support organizations applied for the elder service project, this may not seem relevant to the mission of supporting. Support organizations that serve as an incubator also could achieve good results, but the primary inputs and one-time implement are not directly related to the improvement of platform functions.

In summary, many support organizations chose to do social service projects or projects which could be easily measured by visible outputs or products like professional research, training system, branding. And social organizations that had close relationship with the government were more likely to receive large grants. This intermittent operation mode is not conducive to the role of support platform and the function of innovative social governance.

\section{Conclusion and Thinking}

After practice of many years, the government guided venture philanthropy in China had formed many successful cases with local features, but there are also many shortcomings. Those VP practices mostly focused on short-term projects and regulated the implementation by rewards and punishments. Concepts of government purchase and venture philanthropy are mixed to some degree. More importantly, the government's strict restrictions on social organizations will make their development goals "driven by the will of the government" [20], putting excessive incentives on collective action started from voluntary will easily break the cooperation basis and crowd out the inherent motivation, which 
may cause deviation results. Excessive regulation will also crowd out the voluntary donation from enterprises, individuals and foundations, affect the broadness of society participation.

It can be seen that investors need to have a good knowledge of the real needs and the internal development tendency before imposed external incentives on them. Blindly using rules will interrupt the internal operating mechanism of funded organizations and trigger their "rebelliousness". And those organizations have no opportunity to negotiate, and have to adjust themselves to the rules and temporarily give up the original autonomy. Both of these conditions are not conducive for the NGOs' to improve their capability and the status quo, and the fund given by the investor, "wishing only to do good, often cannot help doing harm". In the future practice of venture philanthropy, the government should still take the promotion of capacity building of social organizations as its starting point, create a free and inclusive environment for venture philanthropy and coordinate the compulsory and service/values policies.

\section{References}

[1] Sievers, B. (1997) If Pigs Had Wings: The Appeals and Limits of Venture Philanthropy. Foundation News \& Commentary, 11/12.

[2] Ostrom, E. (2015) Policies for Extruding Reciprocity and Collective Action. In: Patti, H., et al., Eds., Translated by Li Fenghua, et al., Moral Emotions and Material Benefits-Basis for Cooperation in Economic Life, China Renmin University Press, Beijing, 243-265.

[3] Letts, C.W., Ryan, W. and Grossman, A. (1997) Virtuous Capital: What Foundations Can Learn from Venture Capitalists. Harvard Businessman Review, No. 4, 91-109.

[4] Zhaonan, Z. and Ji, M. (2016) Venture Philanthropy-A New Way of Charity Funding-Experience of America Practice. China Social Organization, No. 2, 18-21.

[5] Qihai, C. (2011) Venture Philanthropy: A New Model to Cultivate NGOs-A Case Study of "Shanghai Community Venture Philanthropy Competition". Hangzhou: Wo Men, (3).

[6] Titmuss, R.M. (1970) The Gift Relationship. From Human Blood to Social Policy. The Gift Relationship: From Human Blood to Social Policy. Allen \& Unwin.

[7] Carlson, N. (2000) Enlightened Investment or Excessive Intrusion? Amministrazione \& Finanza, 11

[8] Gintis, H., Bowles, S., Boyd, R., et al. (2005) Moral Sentiments and Material Interests: Origins, Evidence, and Consequences. General Information, 109, 380-381.

[9] Vollan, B. (2008) Socio-Ecological Explanations for Crowding-Out Effects from Economic Field Experiments in Southern Africa. Ecological Economics, 67, 560-573. https://doi.org/10.1016/j.ecolecon.2008.01.015

[10] Jacobsen, C.B., Hvitved, J. and Andersen, L.B. (2013) Command and Motivation: How the Perception of External Interventions Relates to Intrinsic Motivation and Public Service Motivation. Public Administration, 92, 790-806. https://doi.org/10.1111/padm.12024

[11] Hughes, P., Luksetich, W. and Rooney, P. (2014) Crowding-Out and Fundraising Efforts. Nonprofit Management and Leadership, 24, 445-464. 
https://doi.org/10.1002/nml.21102

[12] Notice about Publishing "Guangzhou NGO Venture Philanthropy Project Management Approach”. Guangzhou Civil Affairs Bureau, 2013-10-28.

http://sfzb.gzlo.gov.cn/sfzb/file.do?fileId=2C90892540DDB8440141EEF50DE100A2

[13] Chunhua, L. (2015) Could VP Lower Its Threshold. Southern Metropolis Daily, 2015-05-19(10).

[14] 2015 Annual Report of Guangzhou Civil Affairs Bureau. Guangzhou Civil Affairs Bureau Website. 2016-04-25.

[15] Frumkin, P. (2003) Inside Venture Philanthropy. Society, 40, 7-15. https://doi.org/10.1007/s12115-003-1013-0

[16] Mai, H. (2016) Guangzhou Second Public Philanthropy Competition Announced Results-More than Half of the Projects Got High Scores, Directly Help More than 400,000 People. 2016-1-12(8).

[17] Brown, L.D. (1991) Bridging Organizations and Sustainable Development. Human Relations, 44, 807-831. https://doi.org/10.1177/001872679104400804

[18] Yushan, X. (2010) Innovation of Social Organizational Structure: Growth of Supporting Organizations. China Social Organization, No. 8, 28-31.

[19] Haiyan, L. and Bo, H. (2012) Research on Government Purchasing from Supporting Social Organizations-A Case Study of Haishu District, Ningbo City, Zhejiang Province. Inner Mongolia Social Organization, 33, 22-26.

[20] Yan, R.S. (2010) Governmental Lineation and Adaptive Governance of Non-Government Organizations in China. Management World, 7, 167-168. 